\title{
AVALIAÇÃO DA QUALIDADE DE VIDA NO TRABALHO DE DOCENTES UNIVERSITÁRIOS
}

\section{EVALUATION OF THE LIFE QUALITY IN THE WORK OF UNIVERSITY DOCENTS}

\section{EVALUACIÓN DE LA CALIDAD DE VIDA EN EL TRABAJO DE DOCENTES UNIVERSITARIOS}

Açucena Leal de Araújo ${ }^{1}$, Érica de Moura Fé ${ }^{2}$, Dinah Alencar de Melo Araújo ${ }^{3}$, Ellaine Santana de Oliveira ${ }^{4}$, Ionara Holanda de Moura ${ }^{5}$, Ana Roberta Vilarouca da Silva ${ }^{6}$.

\section{RESUMO}

Objetivo: Analisar a qualidade de vida no trabalho de docentes de uma universidade pública. Métodos: Trata-se de um estudo de caráter descritivo e transversal, de abordagem quantitativa. Realizado com n=102 docentes de uma instituição de ensino superior pública, localizada no Centro-Sul piauiense. Fez-se uso do instrumento criado por Walton, validado e adaptado à realidade do trabalho docente. Esse instrumento compreende oito dimensões referentes à qualidade de vida no trabalho, mensurando o nível de satisfação laboral com questões do tipo Likert. Os dados foram organizados por meio do software Excel 8.0 e processados no programa estatístico IBM Statistical Package for the Social Sciences. Resultados: Foi observado que, das oito dimensões analisadas referentes à qualidade de vida no trabalho, três (Compensação Justa e Adequada; Oportunidade de Crescimento e Segurança; e Trabalho e Espaço Total de Vida) apresentaram-se com escores de insatisfação por parte dos docentes; enquanto, nas demais, observaram-se escores de indiferença. Conclusão: Espera-se que os resultados levantados neste estudo contribuam para a reflexão, além de nortear ações que visem à manutenção, prevenção e promoção de aspectos pertinentes à qualidade de vida no trabalho docente, colaborando com a promoção de políticas institucionais que valorizem a qualidade do trabalho desses profissionais.

Descritores: Qualidade de Vida; Trabalho; Docentes; Universidades; Saúde do Trabalhador.

\begin{abstract}
Objective: To analyze the life quality in the work of university docents. Methods: This is a descriptive and cross-sectional study, with a quantitative approach. It was carried out with $n=102$ docents from a public higher education institution, located in CenterSouth of Piauí. The instrument created by Walton was used, validated and adapted to the reality of the teaching work. This instrument comprises eight dimensions concerning Life Quality at work, measuring the level of job satisfaction with Likert-type questions. The data were organized using Excel 8.0 software and processed in the statistical program IBM Statistical Package for the Social Sciences. Results: It was observed that of the eight dimensions analyzed concerning the life quality at work, three (Fair and Adequate Compensation, Opportunity for Growth and Safety, and Work and Total Living Space) presented with scores of professors' dissatisfaction, while, in the others, indifference scores were observed. Conclusion: It is expected that the results presented in this study will contribute to reflection, in addition to orient actions aimed at maintenance, prevention, and promotion of aspects pertinent to life quality in the teaching work. Collaborating with the institutional policies promotion that aims to value these professionals' work quality.
\end{abstract}

Keywords: Life Quality; Work; Docents; Universities; Worker's Health.

\section{RESUMEN}

Objetivo: Analizar la calidad de vida en el trabajo de profesores de una universidad pública. Métodos: Se trata de un estudio de carácter descriptivo y transversal, de abordaje cuantitativo. Realizado con $n=102$ profesores de una Institución de Enseñanza Superior pública, ubicada en el centro-sur de Piauí. Se hizo uso del instrumento creado por Walton, validado y adaptado a la realidad del trabajo de profesores universitarios. Este instrumento comprende ocho dimensiones referentes a la Calidad de Vida en el Trabajo, midiendo el nivel de satisfacción laboral con cuestiones del tipo Likert. Los datos fueron organizados a través del software Excel 8.0 y procesados en el programa estadístico de IBM Statistical Package for the Social Sciences. Resultados: Se fue observado que, de las ocho dimensiones analizadas referentes a la calidad de vida en el trabajo, tres (Compensación Justa y Adecuada, Oportunidad de Crecimiento y Seguridad, y Trabajo y Espacio Total de Vida) se presentaron con puntuaciones de insatisfacción por parte de los profesores, mientras que, en las demás, se observaron puntuaciones de indiferencia. Conclusión: Se espera que los resultados levantados en este estudio contribuyan a la reflexión, además de orientar acciones que visen mantenimiento, prevención y promoción en los aspectos pertinentes a la calidad de vida en el trabajo de profesores y pueda colaborar con la promoción de políticas institucionales que apunte a la valorización y calidad del trabajo de estos profesionales. Descriptores: Calidad de Vida; Trabajo; Profesores universitarios; Universidades; Salud Laboral.

${ }^{1}$ Acadêmica de Enfermagem da UFPI. ${ }^{2}$ Acadêmica de Enfermagem da UFPI. ${ }^{3}$ Acadêmica de Enfermagem da UFPI. ${ }^{4}$ Nutricionista da UFPI. ${ }^{5}$ Enfermeira. Mestre em Ciências da Saúde. ${ }^{6}$ Departamento de Enfermagem da UFPI.

Como citar este artigo:

Araújo AL, Fé EM, Araújo DAM, et al. Avaliação da Qualidade de Vida no Trabalho de Docentes Universitários.Revista de Enfermagem do Centro Oeste Mineiro. 2019;9: e3195. [Access___]; Available in:__. DOI: http://dx.doi.org/10.19175/recom.v9i0.3195 


\section{INTRODUÇÃO}

A Qualidade de Vida (QV) é difundida na contemporaneidade e representa um conceito multidisciplinar e polissêmico ${ }^{(1)}$. De acordo com a Organização Mundial de Saúde (OMS), a QV é "a percepção dos indivíduos de que suas necessidades são satisfeitas ${ }^{(2)}$, transcendendo o aspecto físico e mental. A QV adentra os aspectos individuais e coletivos dos sujeitos no trabalho, trazendo à tona a Qualidade de Vida no Trabalho (QVT).

A QVT se relaciona com aspectos intrínsecos e extrínsecos às condições de vida no âmbito laboral, envolvendo bem-estar, garantia da saúde, segurança física, mental, social e capacitação para realizar tarefas com segurança e bom uso da energia pessoal. Trata, ainda, da promoção da saúde e prevenção de doenças relacionadas ao trabalho, além de apresentar impacto econômico ao promover condições favoráveis ao trabalho, diminuindo incapacidade laboral e aposentadoria precoce ${ }^{(3-4)}$. Walton (1973) foi o primeiro a conceituar QVT, propondo um modelo com oito dimensões, conceituando-a como um processo pelo qual a organização responde às necessidades dos funcionários, promovendo mecanismos que contribuam para que as pessoas participem da tomada de decisões que protejam suas vidas no trabalho ${ }^{(5-6)}$. Os níveis de QVT aumentam na presença de bem-estar psicológico, ausência de sofrimento psicológico, compromisso com a organização, responsabilidade com o trabalho e equilíbrio entre vida profissional e vida pessoal ${ }^{(7-8)}$.

A partir dos conceitos de QV e QVT, não raro, é possível destacar o ambiente universitário como gerador de fatores desgastantes, pois os professores universitários possuem rotinas intensas, com preparação e realização de aulas, além de atender outras demandas decorrentes da função, independentemente do tipo de organização na qual estejam inseridos. Há necessidade de gerar um ambiente laboral de integração, com bem-estar do trabalhador e eficácia organizacional ${ }^{(9-10)}$, pois há exigências para lidar com novas tecnologias de ensinoaprendizagem, atender à crescente demanda por produtividade acadêmica, corresponder às exigências de aprimoramento intelectual e de qualidade na educação e para contribuir com a construção do conhecimento científico ${ }^{(11)}$.

Ora, a saúde dos professores universitários é foco da preocupação de segmentos variados da sociedade, pois este trabalhador é alvo de grande pressão social pela necessidade de demonstrar bom desenvolvimento em seu trabalho. Assim, o docente se desgasta psicológica, física e emocionalmente, o que pode ocasionar estresse, depressão e sentimentos de insatisfação profissional devido ao esforço para ser um bom professor $^{(12-13)}$. Assim, há necessidade de intervenções no ambiente de trabalho para amenizar as dificuldades atreladas às atividades laborais e promover a saúde no campo docente. Para superar esses entraves, os gestores universitários podem se valer de várias alternativas, inserindo um ambiente de trabalho saudável e estimulante, que favoreça o equilíbrio psicossocial dos profissionais, melhorando a QVT.

$O$ presente estudo teve como objetivo analisar a Qualidade de Vida no Trabalho (QVT) de docentes de uma universidade pública do Centro-Sul piauiense.

\section{MÉTODOS}

Trata-se de um estudo quantitativo transversal, realizado em uma Instituição de Ensino Superior (IES) pública localizada no município de Picos-PI.

A pesquisa foi realizada com os professores efetivos da IES, constituída por um público de 153 docentes de ambos os sexos, que se encontravam ativos durante o período da coleta de dados. Foram considerados como critérios de inclusão: atuar como docente efetivo da IES; e, como critério de exclusão: tempo de docência inferior a um ano, docentes apenas da modalidade de Educação a Distância - EAD e pós-graduação, e estar afastado por algum motivo. A amostra totalizou 102 docentes participantes.

As variáveis deste estudo foram agrupadas em Qualidade de Vida no Trabalho e características socioeconômicas relacionadas à QVT. No primeiro grupo, foram investigados: condições de trabalho, compensação justa e adequada, uso e desenvolvimento de capacidades, oportunidade de crescimento e segurança, integração social na organização, direitos e deveres, trabalho e espaço total de vida e relevância social da vida no trabalho. No segundo grupo, investigou-se: sexo, idade, renda, número de filhos, com quem mora, área, tempo de docência, titulação e carga horária semanal.

Para avaliar a QVT, utilizou-se o instrumento criado por Walton, validado $\mathrm{e}$ adaptado à realidade do trabalho docente ${ }^{(14-15)}$. Esse instrumento compreende oito dimensões referentes à QVT, sendo possível mensurar o 
nível de satisfação no âmbito laboral, com questões fechadas do tipo Likert, composto por variáveis de um a seis, na seguinte distribuição: Muito Insatisfeito, Insatisfeito, Indiferente, Satisfeito, Muito Satisfeito, e Não se Aplica. As oito dimensões dizem respeito a: Condições de Trabalho; Compensação Justa e Adequada; Uso e Desenvolvimento de Capacidades; Oportunidade de Crescimento e Segurança; Integração Social na Organização; Direitos e Deveres; Trabalho e Espaço Total de Vida; e Relevância Social da Vida no Trabalho, respectivamente.

A coleta foi realizada pela pesquisadora responsável e pelos integrantes do Programa de Educação Tutorial (PET), previamente treinados, no período de setembro a outubro de 2017. O convite para participar da pesquisa aconteceu via e-mail, em sala de aula e/ou pelas dependências da IES. Na ocasião, foram explicados os objetivos, o método e os aspectos éticos do estudo. Aqueles que manifestaram $o$ desejo de participar responderam aos instrumentos em sala reservada e de forma individual na própria instituição, antecedendo a assinatura do Termo de Consentimento Livre e Esclarecido em duas vias.

Os dados foram organizados por meio do software Excel 8.0 e processados no programa estatístico IBM Statistical Package for the Social Sciences (SPSS) versão 20.0, resultando em um banco de dados e dispostos na forma de tabelas com apresentação descritiva das frequências absoluta e relativa, além de serem realizados testes estatísticos Annova e Qui-Quadrado entre as variáveis da QVT, aplicando-se $p<0,05$ como valor de referência para a significância estatística.

O projeto foi aprovado pelo Comitê de Ética em Pesquisa da Universidade Federal do Piauí - UFPI, sob parecer número 2.269.341, com Certificado de Apresentação para Apreciação Ética (CAAE) 68708617.9.0000.8057, respeitandose todos os aspectos éticos preconizados pelas normas da Resolução 466/12 $2^{(16)}$.

\section{RESULTADOS E DISCUSSÃO}

Os $102(100 \%)$ docentes pesquisados eram de onze cursos da instituição. Desses, 56 (54,9\%) eram do sexo feminino. A maioria encontrava-se na faixa etária de 34 a 45 anos (51,0\%). A cor autorreferida predominante foi a parda $(47,1 \%)$. A maioria dos participantes só trabalhava $(57,8 \%) ; 42,2 \%$ estudavam e trabalhavam. A renda familiar esteve concentrada em uma faixa igual ou superior a seis salários mínimos mensais $(46,1 \%)$, com média de $\mathrm{R} \$ \mathbf{8 . 0 0 0 , 0 0}+\mathrm{R} \$$
3.480,25. A classe econômica predominante foi a B2 (46,1\%). Em relação à situação conjugal, 56,9\% dos docentes afirmaram ser casados e sem filhos $(52,9 \%)$, predominando docentes naturais de outras localidades $(85,3 \%)$ e que moravam com o companheiro(a), 44,1\%.

Em relação às variáveis institucionais, predominaram os professores que exerciam a docência entre 1 e 3 anos $(44,1 \%)^{(17)}$; com a maioria possuindo Doutorado (40,2\%). Entretanto, esse resultado divergiu do encontrado em uma pesquisa ${ }^{(18)}$ em que os professores de cinco cursos da área da saúde possuíam maior grau de formação em mestrado. A maioria afirmou trabalhar 40 horas semanais em regime de dedicação exclusiva (92,2\%), sendo nos turnos manhã/tarde $50,0 \%$, disponibilizando 3 a 4 horas para atividades extraclasse, e para atividades burocráticas, com percentual de 55,9\% e $48,0 \%$, respectivamente. Percentual considerável dos docentes $(39,2 \%)$ afirmou exercer atividade extra dentro da instituição, entretanto, a maior parte desse percentual $(21,6 \%)$ ressaltou não ser remunerada por isso.

Para entender melhor como a estrutura do ambiente de trabalho dos docentes interfere na QVT, os participantes da pesquisa foram questionados em relação a aspectos pertinentes à disponibilidade de serviços e o acesso a esses. Quando questionados se a instituição possuía climatização em salas de aula, 97,1\% afirmaram que sim. Em relação aos equipamentos disponibilizados pela instituição, 73,5\% responderam que o órgão dispõe de projetor multimídia e notebook. Questionados sobre qual desses utilizavam com maior frequência, 97,1\% responderam que faziam uso do aparelho multimídia.

Em consonância com a evolução tecnológica, os professores foram questionados se a instituição dispunha de acesso à internet via rede wireless ou via cabo com o intuito de facilitar o trabalho docente. $94,1 \%$ afirmaram fazer uso dessa ferramenta. Já em relação à instituição contar com espaços de lazer, 52,9\% responderam que o órgão não possuía esses locais; em contrapartida, 36,3\% responderam que a universidade conta com praças e áreas de convívio ao ar livre. Dos participantes que responderam que a universidade possui espaços de lazer, $31,4 \%$ não fazem uso desses espaços. 
Tabela 1 - Caracterização do perfil da Qualidade de Vida no Trabalho - QVT. Picos - PI, 2017. (n=102).

\section{CONDIÇÕES DE TRABALHO}

Carga horária para as atividades de professor

Carga horária das atividades extraclasse

Equipamentos e materiais disponíveis

Qualidade dos equipamentos e materiais

Conforto do ambiente físico

Limpeza do ambiente físico

Infraestrutura do ambiente físico para o exercício das atividades de

professor

Condições de segurança e de saúde para execução das atividades de

professor

\section{COMPENSAÇÃO JUSTA E ADEQUADA}

Salário pago pelas atividades de professor

Plano de benefícios oferecido pela universidade

Equidade salarial interna

Equidade salarial externa

Remuneração das atividades extraclasse (preparação de provas e aulas etc.)

\section{USO E DESENVOLVIMENTO DE CAPACIDADES}

Feedback dos alunos sobre o trabalho dos professores

Feedback dos superiores sobre os trabalhos dos professores

Autonomia do trabalho do professor

Utilização do conhecimento profissional como professor

Utilização do conhecimento científico como professor

Aplicação da criatividade como professor

Influência que a atividade do docente tem sobre a vida profissional dos

alunos

Influência que a atividade do docente tem sobre

a vida pessoal dos alunos

\section{OPORTUNIDADE DE CRESCIMENTO E SEGURANÇA}

Estabilidade na universidade

Incentivo da universidade para realização de mestrado

Incentivo da universidade para realização de doutorado

Incentivo da universidade para realização de atividades de pesquisa

Incentivo da universidade para realização de atividades administrativas

Incentivo da universidade para realização de atividades de consultoria

Plano de carreira oferecido pela universidade

Possibilidade de ascensão na universidade

Treinamento e reciclagem de novas tecnologias e metodologia de ensino

Incentivos financeiros para atualização de docentes (seminários,

congressos)

\section{INTEGRAÇÃO SOCIAL NA ORGANIZAÇÃO}

Igualdade de tratamento e oportunidades

Relacionamento entre professores na universidade

Relacionamento com os alunos

Relacionamento entre superiores e professores

\section{DIREITOS E DEVERES}

Cumprimento de obrigações

Liberdade de expressão na universidade

Liberdade de expressão em sala de aula

Respeito à privacidade pessoal na universidade

\section{TRABALHO E ESPAÇO TOTAL DE VIDA}

Equilíbrio entre o tempo dispensado no trabalho de professor e na vida pessoal

Tempo para a vida familiar

Tempo para lazer

\section{RELEVÂNCIA SOCIAL DA VIDA NO TRABALHO}

Fato de a universidade procurar prestar serviços de boa qualidade aos clientes(alunos)

Imagem da universidade na comunidade

$\begin{array}{cccccc}\begin{array}{c}\text { MI* } \\ \%\end{array} & \begin{array}{c}\mathbf{I \dagger} \\ \%\end{array} & \begin{array}{c}\mathbf{N} \% \\ \%\end{array} & \begin{array}{c}\mathbf{S} \S \\ \%\end{array} & \begin{array}{c}\text { MS|I } \\ \%\end{array} & \begin{array}{c}\mathbf{N a ̃} \\ \%\end{array} \\ 6,9 & 19,6 & 6,9 & 56,9 & 9,8 & - \\ 9,8 & 31,4 & 15,7 & 37,3 & 4,9 & 1,0 \\ 6,9 & 33,3 & 10,8 & 43,1 & 5,9 & - \\ 7,8 & 28,4 & 12,7 & 42,2 & 7,8 & 1,0 \\ 4,9 & 19,6 & 11,8 & 53,9 & 9,8 & - \\ 2,0 & 4,9 & 5,9 & 64,7 & 22,5 & - \\ 8,8 & 30,4 & 7,8 & 42,2 & 10,8 & - \\ & & & & & \\ 3,9 & 19,6 & 20,6 & 48,0 & 7,8 & -\end{array}$

16,7

21,6

13,7

23,5

25,5

4,9

7,8

2,0

1,0

1,0

1,

$$
\text { - }
$$$$
1,0
$$

4,9

44,1

43,1

23,5

36,3

28,4

19,6

22,5

13,7

9,8

8,8

5,9

5,9

4,9

25

2,9

2,

5,9

5,9
11,8

11,8
8,8

8,8
14,7

14,7
14,7

14,7
8,8

23,5

36,3

8,8

11,8

14,7

40,2

30,4

26,5

40,2

37,3

36,3

36,3

.

\section{$-$}

2,0

3,9

3,9

- 2,0

6,9

24,5

23,5

20,6

39,2

37,3

13,7

17,6

24,5

12,7
25,5

17,6

30,4

11,8

(1)

49,0

38,2

55,9

55,9

58,8

$58,8 \quad 19,6$

$65,7 \quad 17,6$

$52,0 \quad 9,8$

1,0

6,9

$66,7 \quad 14,7$

$39,2 \quad 4,9$

$43,1 \quad 6,9$

$23,5 \quad 2,0$

$15,7 \quad 2,0$

$7,8 \quad-$

$30,4 \quad 1,0$

$32,4 \quad 3,9$

$10,8 \quad 1,0$

12,7 -

\begin{tabular}{cccccc}
17,6 & 33,3 & 9,8 & 35,3 & 3,9 & - \\
12,7 & 41,2 & 8,8 & 32,4 & 4,9 & - \\
18,6 & 39,2 & 8,8 & 28,4 & 4,9 & - \\
2,9 & 9,8 & 15,7 & 68,6 & 2,9 & - \\
2,0 & 11,8 & 5,9 & 64,7 & 14,7 & 1,0 \\
\hline \multicolumn{5}{c}{ "continua na página seguinte". }
\end{tabular}

$\begin{array}{llll}11,8 & 63,7 & 11,8 & 1,0\end{array}$

Nãף
$\%$
1,0
1,0




\begin{tabular}{|c|c|c|c|c|c|c|}
\hline & $\begin{array}{c}\text { MI* } \\
\%\end{array}$ & $\begin{array}{l}\text { It } \\
\%\end{array}$ & $\begin{array}{c}\mathrm{N} \ddagger \\
\%\end{array}$ & $\begin{array}{l}\text { S § } \\
\%\end{array}$ & $\begin{array}{c}\text { MS|I } \\
\%\end{array}$ & $\begin{array}{c}\text { Nãq } \\
\%\end{array}$ \\
\hline Conceito da universidade nos órgãos públicos & 2,0 & 8,8 & 10,8 & 61,8 & 16,7 & - \\
\hline Universidade se preocupar com a comunidade & 1,0 & 21,6 & 23,5 & 49,0 & 3,9 & 1,0 \\
\hline Responsabilidade social pelos professores & 2,9 & 22,5 & 26,5 & 41,2 & 4,9 & 2,0 \\
\hline Forma de gestão de RH adotada pela universidade & 4,9 & 18,6 & 28,4 & 42,2 & 3,9 & 2,0 \\
\hline
\end{tabular}

Fonte: Dados da pesquisa MI*: Muito Insatisfeito; I†: Insatisfeito; N‡: Indiferente; S§: Satisfeito; MS| |: Muito Satisfeito; Não se aplica.

Observa-se, no Gráfico 1, nos dados referentes à compilação por dimensão, em relação à QVT, que três dimensões foram avaliadas pelos professores como Insatisfeitas (Compensação Justa e Adequada; Oportunidade de Crescimento e Segurança; e Trabalho e Espaço Total de Vida), enquanto as demais ficaram no patamar de indiferença.

A dimensão Compensação Justa e Adequada foi a que apresentou maior grau de insatisfação por parte dos professores. Em um estudo comparativo com professores de duas universidades, uma pública e outra privada, constatou-se que os docentes da instituição pública encontravam-se mais insatisfeitos a respeito dessa categoria ${ }^{(19)}$.

$\mathrm{Na}$ dimensão Oportunidade de Crescimento e Segurança verificou-se a insatisfação por parte dos docentes, sobretudo em relação à falta de incentivo pela universidade para realização de atividades de pesquisa, atividades administrativas, plano de carreira e oportunidade de ascensão profissional. Em uma pesquisa ${ }^{(20)}$ comparativa sobre QVT realizada com docentes universitários do Canadá e do Brasil, constatou-se que os professores canadenses possuem maior autonomia no trabalho, mais oportunidades para o desenvolvimento profissional, além de possuírem maior reconhecimento profissional por suas atividades desempenhadas quando comparados aos docentes brasileiros.

Ao analisar a dimensão Trabalho e Espaço Total de Vida, evidenciou-se que os professores estavam insatisfeitos, principalmente, em relação à pouca disposição de tempo para a família e para o lazer ${ }^{(21-22)}$. Por isso, o trabalho dos professores universitários pode ser visto como fundamental e influenciador no estilo e na QVT desses profissionais, pois boa parte das horas do dia é dedicada às atividades laborais ${ }^{(23)}$.

Gráfico 1 - Médias gerais e desvio padrão da QVT da amostra, por categoria. Picos - PI, 2017.

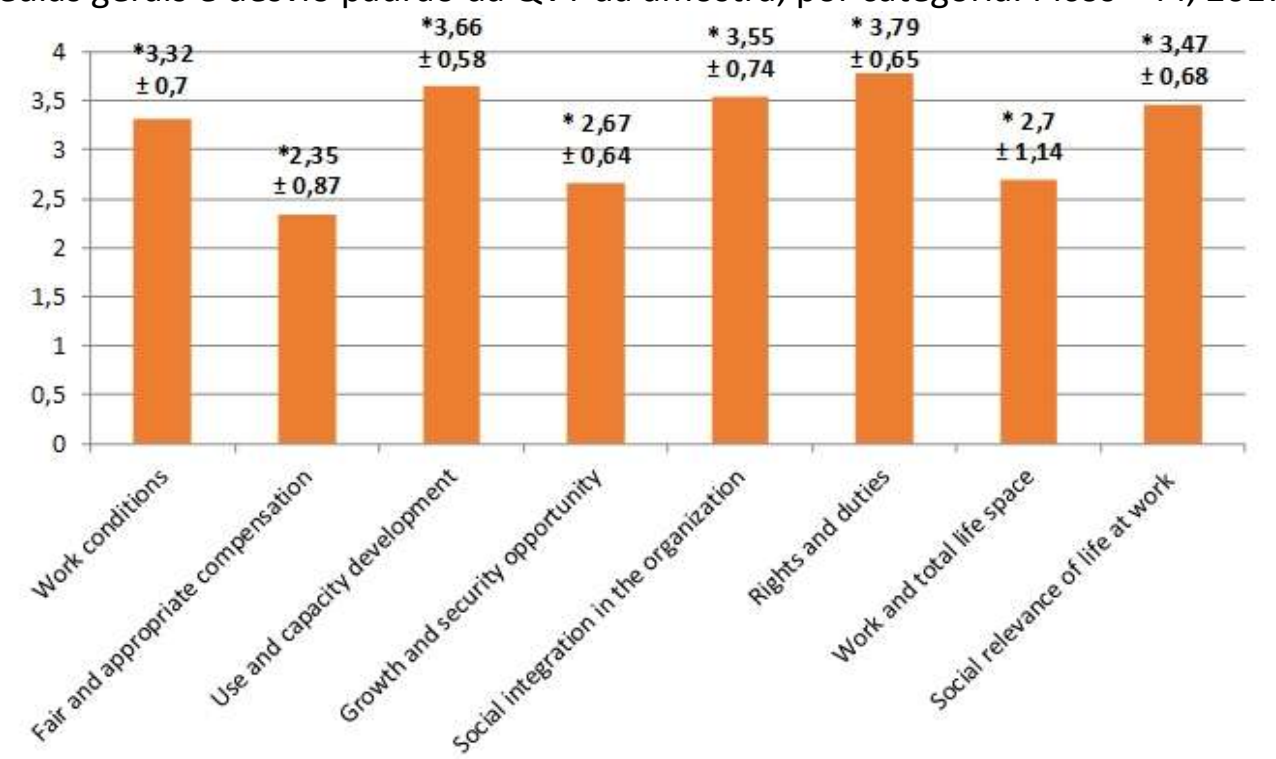

Fonte: Dados da pesquisa. *Média e Desvio Padrão.

Na Tabela 2, é possível observar que a média da QVT, de acordo com as variáveis sociodemográficas, demonstrou que o sexo influenciou diretamente na QVT, pois o sexo masculino apresentou maior QVT, com média de 3,36 , além de ser estatisticamente significante $p=0,001$. Os docentes sem filhos ou com até um filho foram as categorias que obtiveram melhor média da QVT, sendo estatisticamente significante $\mathrm{p}=0,015$. 
A variável com quem a pessoa morava também obteve relação estatisticamente significante $(p=0,025)$, evidenciando que os docentes que moravam com os amigos possuíam uma melhor QVT, com média de 3,92.

Tabela 2 - Análise de médias das dimensões da QVT em relação às variáveis sexo, idade e perfil profissional. Picos - PI, 2017.

\begin{tabular}{|c|c|c|}
\hline Variáveis & Qualidade de Vida no Trabalho & p-valor \\
\hline Sexo & & $0,001+$ \\
\hline Feminino & $3,04 \pm 0,47^{*}$ & \\
\hline Masculino & $3,36 \pm 0,48^{*}$ & \\
\hline Idade & & $0,389 \ddagger$ \\
\hline Até 24 anos & $3,46^{*}$ & \\
\hline $25-33$ anos & $3,30 \pm 0,46^{*}$ & \\
\hline $34-44$ anos & $3,12 \pm 0,54^{*}$ & \\
\hline$\geq 45$ anos & $3,13 \pm 0,42 *$ & \\
\hline Renda & & $0,387 \ddagger$ \\
\hline 4 salários & $3,56 \pm 0,22^{*}$ & \\
\hline 5 salários & $3,05 \pm 0,30 *$ & \\
\hline$\geq 6$ salários & $3,19 \pm 0,519 *$ & \\
\hline Número de filhos & & $0,015 \ddagger$ \\
\hline Zero & $3,21 \pm 0,47^{*}$ & \\
\hline Um & $3,37 \pm 0,33^{*}$ & \\
\hline Dois & $2,92 \pm 0,60^{*}$ & \\
\hline Três ou mais & $2,88^{*}$ & \\
\hline Com quem mora & & $0,025 \ddagger$ \\
\hline Pais & $3,15 \pm 0,21 *$ & \\
\hline Familiares & $3,30 \pm 0,40 *$ & \\
\hline Amigos & $3,92 \pm 0,69 *$ & \\
\hline Companheiro (a) & $3,03 \pm 0,39 *$ & \\
\hline Sozinho & $3,30 \pm 0,68$ & \\
\hline Área & & $0,861 \ddagger$ \\
\hline Humanas & $3,22 \pm 0,43^{*}$ & \\
\hline Ciências Biológicas/Saúde & $3,16 \pm 0,55^{*}$ & \\
\hline Exatas & $3,17 \pm 0,49 *$ & $0,922 \ddagger$ \\
\hline \multicolumn{3}{|l|}{ Tempo de Docência } \\
\hline $1-3$ anos & $3,22 \pm 0,43^{*}$ & \\
\hline $4-6$ anos & $3,13 \pm 0,70^{*}$ & \\
\hline $7-9$ anos & $3,16 \pm 0,39 *$ & \\
\hline$\geq 10$ anos & $3,16 \pm 0,63^{*}$ & \\
\hline Titulação & & $0,638 \ddagger$ \\
\hline Especialista & $3,26 \pm 0,48^{*}$ & \\
\hline Mestrado & $3,23 \pm 0,44^{*}$ & \\
\hline Doutorado & $3,11 \pm 0,57^{*}$ & \\
\hline Pós-doutorado & $3,11 \pm 0,41 *$ & \\
\hline Carga horária semanal & & $0,997 \ddagger$ \\
\hline $40 h$ & $3,21 \pm 0,17^{*}$ & \\
\hline $20 \mathrm{~h}$ & $3,18 \pm 0,48^{*}$ & \\
\hline 40h dedicação exclusiva & $3,18 \pm 0,51^{*}$ & \\
\hline
\end{tabular}

Fonte: Dados da pesquisa. * Média e desvio padrão. †Teste t-Student para amostras independentes. ‡ ANNOVA One-Way.

A pesquisa possibilitou identificar a QVT de 102 docentes universitários nas oito dimensões propostas por Walton e adaptada à realidade dos docentes universitários, permitindo demonstrar os aspectos que influenciam direta $e$ indiretamente na vida desses profissionais, contribuindo, assim, para a importância de intervenções assertivas no ambiente laboral.

A influência da organização do âmbito laboral na saúde e no desempenho dos profissionais diverge de acordo com a percepção de cada sujeito e suas características pessoais. Neste estudo, elencaram-se resultados que demonstram, nas dimensões referentes à Compensação Justa e Adequada; Oportunidade de Crescimento e Segurança; e Trabalho e Espaço Total de Vida, que o grau de insatisfação foi analisado de forma marcante em comparação às demais dimensões, com as quais os docentes se mostraram indiferentes.

Esses resultados demonstram que, apesar de, em grande parte, os docentes estarem 
indiferentes, não foi possível observar de forma acentuada a presença de níveis de satisfação nas dimensões pesquisadas, o que caracteriza a neutralidade por parte do público investigado a respeito de sua QVT. Esses fatores ocasionam um problema organizacional, podendo interferir no crescimento da instituição e na QVT, pois oferta pouca aspiração de crescimento, tanto pessoal quanto coletivo.

Além disso, o trabalho docente pode culminar, muitas vezes, em um intenso desgaste cognitivo, pois os profissionais enfrentam jornadas de trabalho de $\mathbf{4 0}$ horas semanais, além de terem que dispor de tempo para participar de atividades extraclasse, atividades burocráticas, além de estarem inseridos no campo da pesquisa.

Em contrapartida, é indispensável que as universidades ampliem suas perspectivas organizacionais acerca da QVT, através de programas e diretrizes que se preocupem com a seguridade social, as relações de trabalho, o plano de carreira, a remuneração e o dimensionamento da força de trabalho, pois com essas implementações, será possível minimizar desgastes psicológicos, físicos e emocionais.

\section{CONCLUSÃO}

A análise da QVT de docentes de uma IES mostrou que, percentual considerável dos professores encontrava-se insatisfeito em relação à QVT em três importantes dimensões (Compensação Justa e Adequada; Oportunidade de Crescimento e Segurança; e Trabalho e Espaço Total de Vida). Enquanto isso, nas demais dimensões avaliadas, constatou-se maior percentual de indiferença, o que representa uma preocupação, tendo em vista que mantiveram neutralidade em torno das questões levantadas.

Assim, sugere-se a adoção de estratégias que visem à promoção da QVT, atuando, principalmente, nas dimensões onde foram identificados maior grau de insatisfação por parte do público em questão, além de buscar subsídios para a construção de soluções efetivas no contexto organizacional, permitindo, assim, uma maior satisfação pessoal e profissional no campo de atuação docente.

Espera-se que os resultados levantados neste estudo contribuam para a reflexão, além de nortearem ações que visem à manutenção, prevenção e promoção nos aspectos pertinentes à QVT docente, além de sensibilizar os órgãos governamentais e as instituições de ensino superior a respeito dos cuidados referentes a esse fenômeno e à valorização dos professores.

\section{REFERÊNCIAS}

1- Almeida MAB, Gutierrez GL, Marques R. Qualidade de vida: Definição, conceitos e interfaces com outras áreas de pesquisa. São Paulo: Escola de Artes, Ciências e Humanidades da USP; 2012.

2- Fleck MPA, Louzada $S$, Xavier $M$, Chachamovich E, Vieira G, Santos I, et al. Aplicação da versão em português do instrumento abreviado de avaliação da qualidade de vida "whoqol-bref". Rev Saúde Pública 2000;34(2):178-83. DOI: 10.1590/S003489102000000200012

3- Hipólito MCV, Masson VA, Monteiro MI, Gutierrez GL. Qualidade de vida no trabalho: Avaliação de estudos de intervenção. Rev Bras Enferm. 2017;70(1):189-97. DOI: 10.1590/00347167-2015-0069

4- Antloga CS, Carmo MM, Takaki KT. O que é qualidade de vida no trabalho? Representações de trabalhadores de um instituto de pesquisa. Trabalho (En)Cena 2016 [citado em 10 out 2018]; 1(1):132-42. Disponível em: https://sistemas.uft.edu.br/periodicos/index.php Lencena/article/view/2392/9078

5- Ilgan A, Özü-Cengiz O, Ata A, Akram M. The relationship between teachers' psychological wellbeing and their quality of school work life. Journal Happiness Well-Being 2015 [citado em 11 nov 2018]; 3(2):159-81. Disponível em: https://www.researchgate.net/publication/28102 $\underline{7037}$

6- Souza EP, Marques LA, Jorge MAM. Qualidade de vida do trabalho no setor público: Diretrizes para a elaboração de um programa com base em uma experiência junto a um órgão da administração direta do estado de Minas. RGPD 2014 [citado em 5 set 2018]; 5(1):71-87. Disponível em: https://periodicos.ufpe.br/revistas/gestaopublica /article/viewFile/1712/1295

7- Meira TRM, Cardoso JP, Vilela ABA, Amorim $C R$, Rocha SV, Andrade AN, et al. Teachers' perceptions of teaching work and repercussions on their health. Rev Bras Promoc Saúde 2014 [citado em 10 out 2018]; 27(2):276-82. Disponível em:

http://periodicos.unifor.br/RBPS/article/view/25 95/pdf 1

8- Gomes KK, Sanchez HU, Sanchez EGM, Sbroggio Júnior AL, Arantes Filho WM, Silva LA, et 
al. Qualidade de vida e qualidade de vida no trabalho em docentes da saúde de uma instituição de ensino superior. Rev Bras Med Trab. 2017;15(1):18-28. DOI: 10.5327/Z1679443520177027

9- Koetz L, Rempel C, Périco E. Qualidade de vida de professores de instituições de ensino superior comunitárias do Rio Grande do Sul. Ciênc Saúde Coletiva 2013;18(4):1019-28. DOI: 10.1590/S1413-81232013000400015

10- Boas AA, Pires AAS, Faria DA, Morin EM. Indicadores de qualidade de vida no trabalho de docentes de instituições federais de ensino superior das regiões Sudeste, Centro-Oeste e Distrito Federal. Braz Ap Sci Rev. 2018 [citado em 10 out 2018]; 2(1):19-51. Disponível em: http://brjd.com.br/index.php/BASR/article/view/

\section{$\underline{268 / 225}$}

11- Mendonça H, Ferreira MC, Caetano A, Torres $\mathrm{CV}$. Cultura organizacional, coping e bem-estar subjetivo: Um estudo com professores de universidades brasileiras. Rev Psicol, Organ Trab. 2014 [citado em 5 set 2018]; 14(2):230-44. Disponível em: http://pepsic.bvsalud.org/pdf/rpot/v14n2/v14n2 a09.pdf

12- Batista JBV, Carlotto MS, Oliveira MN, Zaccara AAL, Barros EO, Duarte MCS. Mental disorders that most affect university teachers: A study in a medical expertise service. J Res Fund Care 2015;7(1):119-25. DOI: 10.9789/21755361.2015.v7i5.119-125

13- Freire LIF, Fernandez CO. Professor universitário novato: Tensões, dilemas e aprendizados no início da carreira docente. Ciênc Educ. 2015;21(1):255-72. DOI: 10.1590/1516731320150010016

14- Dias GS. Qualidade de vida no trabalho de professores de Administração de empresas: A relação entre uma universidade pública e uma privada [dissertação]. Porto Alegre (RS): Escola de Engenharia, Universidade Federal do Rio Grande do Sul; 2001.

15- Timossi LS, Pedroso B, Pilatti LA, Francisco AC. Adaptação do Modelo de Walton para Avaliação da Qualidade de Vida no Trabalho. Rev Educ Fis UEM 2009;20(3):395-405. DOI: $10.4025 /$ reveducfis.v20i3.5780

16- Brasil. Resolução no 466, de 12 de dezembro de 2012. Diário Oficial da União 2012.

17- Catapan A, Bonfim BLS, Panucci-Filho L, Oliveira EG, Vila EW, Reis EB. Qualidade de Vida no Trabalho (QVT): Uma análise em professores do Ensino Médio e Superior do Brasil. RBQV
2014;6(2):130-18. DOI: $\quad$ 10.3895/S2175$\underline{08582014000200007}$

18- Souto LES, Souza SM, Lima CA, Lacerda MKS, Vieira MA, Costa FM, et al. Fatores associados à Qualidade de Vida de Docentes da Área da Saúde. Rev Bras Educ Méd. 2016;40(3):452-60. DOI: 10.1590/1981-52712015v40n3e02362014

19- Araújo PCD, Maduro MR, Zogahib AL, Lima $\mathrm{OP}$, Silva CJ. Avaliação sobre qualidade de vida no trabalho entre os docentes de duas instituições de ensino superior: Uma realidade no estado do amazonas. Ge Soc. 2016;9(23):961-76. DOI: 10.21171/ges.v9i23.1931

20- Boas AA, Morin EM. Sentido do trabalho e fatores de qualidade de vida no trabalho: A percepção de professores brasileiros e canadenses. Alcance 2016;23(3):272-292. DOI: 10.14210/alcance.v23n3(Jul-Set).p272-292

21- Oliveira RR, Silva IB, Castro SDP, LimongiFrança AC. Qualidade de vida no trabalho (QVT): Um estudo com professores dos Institutos Federais. Holos 2015;6(31):432-447. DOI: 10.15628/holos.2015.1726

22- Pizzio A, Klein K. Qualidade de vida no trabalho e adoecimento no cotidiano de docentes do ensino superior. Educ Soc. 2015;36(131):493513. DOI: 10.1590/ESO101-73302015124201

23- Teixeira LN, Rodrigues AL, Silva FM, Silveira RCP. As possíveis alterações no estilo de vida e saúde de professores. Rev Enferm Cent-Oeste Min. 2015;5(2):1669-83. DOI: $\underline{10.19175 / \text { recom.v0i0.876 }}$

Nota: Artigo resultante do Trabalho de Conclusão de Curso (TCC) intitulado "Avaliação da qualidade de vida no trabalho de docentes universitários", apresentado ao Curso de Bacharelado em Enfermagem, da Universidade Federal do Piauí, 2017.

Recebido em: 04/12/2018

Aprovado em: 02/05/2019

Endereço de correspondência:

Ana Roberta Vilarouca Da Silva

Rua Cícero Eduardo, 905. Junco. CEP: 64600-000 - Picos/PI - Brasil

E-mail: vilarouca@ufpi.edu.br 